\title{
Metabolic investigations prevent liver transplantation in two young children with citrullinemia type I
}

\author{
Martijn J. de Groot • Marcel Cuppen • Marc Eling - Frans W. Verheijen • \\ Edmond H. H. M. Rings • Dirk-Jan Reijngoud • Maaike M. C. de Vries • \\ Francjan J. van Spronsen
}

Received: 1 June 2010 /Revised: 17 August 2010 / Accepted: 27 August 2010 /Published online: 18 September 2010

(C) The Author(s) 2010. This article is published with open access at Springerlink.com

\begin{abstract}
Acute liver failure may be caused by a variety of disorders including inborn errors of metabolism. In those cases, rapid metabolic investigations and adequate treatment may avoid the need for liver transplantation. We report two patients who presented with acute liver failure and were referred to our center for liver transplantation work-up. Urgent metabolic investigations revealed citrullinemia type I. Treatment for citrullinemia type I avoided the
\end{abstract}

Communicated by: James V. Leonard

Competing interests: None declared.

M. J. de Groot • E. H. H. M. Rings · F. J. van Spronsen ( $\square)$ Department of Pediatrics, Division of Metabolic Diseases, Beatrix Children's Hospital, University Medical Center Groningen, University of Groningen,

P.O. Box 30.001, 9700 RB Groningen, The Netherlands

e-mail: f.j.van.spronsen@bkk.umcg.nl

M. J. de Groot • E. H. H. M. Rings • D.-J. Reijngoud •

F. J. van Spronsen

Center for Liver, Digestive and Metabolic Diseases,

GUIDE Graduate School for Drug Exploration,

University Medical Center Groningen, University of Groningen,

Groningen, The Netherlands

M. Cuppen $\cdot$ M. Eling

Department of Pediatrics, Slingeland Hospital,

Doetinchem, The Netherlands

F. W. Verheijen

Department of Clinical Genetics,

Erasmus University Medical Center,

Rotterdam, The Netherlands

M. M. C. de Vries

Department of Metabolic Diseases,

Nijmegen Center for Mitochondrial Disorders,

University Medical Center Nijmegen,

Nijmegen, The Netherlands need for liver transplantation. Acute liver failure as a presentation of citrullinemia type I has not previously been reported in young children. Although acute liver failure has occasionally been described in other urea cycle disorders, these disorders may be underestimated as a cause. Timely diagnosis and treatment of these disorders may avoid liver transplantation and improve clinical outcome. Therefore, urea cycle disorders should be included in the differential diagnosis in young children presenting with acute liver failure.

\section{Introduction}

Acute liver failure, for which liver transplantation is considered, may be caused by a wide variety of diseases. Among these are several inborn errors of metabolism (Table 1). Recent reviews on acute liver failure in children do not mention urea cycle disorders as a cause (Squires 2008; Dhawan 2008). We describe two unrelated patients presenting with acute liver failure, who were referred for liver transplantation. Urgent metabolic work-up revealed citrullinemia type I (OMIM 215700). Treatment resulted in clinical and biochemical improvement, thereby avoiding liver transplantation. These case reports show the importance of urgent and thorough metabolic investigations in young children with acute liver failure referred for liver transplantation.

\section{Patient 1}

Patient 1 was a female Caucasian of healthy nonconsanguineous parents. After an uneventful pregnancy, the patient's mother was referred to a district hospital when fetal decelerations were noted. Vaginal labor was accelerated with vacuum- and forceps extraction. The child was 
Table 1 Inborn errors of metabolism that may present with acute liver failure and associated investigations

\begin{tabular}{ll}
\hline Disorder & Suggested investigations \\
\hline${\text { Tyrosinemia type } \mathrm{I}^{\mathrm{a}-\mathrm{c}}}_{\text {Urea cycle disorders }^{\mathrm{a}, \mathrm{d}}}$ & Blood succinylacetone; urinary OA, succinylacetone, $\delta$-aminolevulinic acid \\
Wilson's disease $^{\mathrm{b}, \mathrm{c}}$ & Blood ammonia, AA; urinary OA, purines/pyrimidines (orotic acid excretion) \\
Neonatal hemochromatosis $^{\mathrm{a}, \mathrm{b}}$ & Blood copper and ceruloplasmin, urinary copper; consult ophthalmologist (evaluation for Kayser-Fleischer ring) \\
Galactosemia $^{\mathrm{a}, \mathrm{b}}$ & Blood ferritin, transferrin, total iron binding capacity, iron \\
Heriditary fructose intolerance $^{\mathrm{a}}$ & Blood galactose; galactose-1-phosphate in erythrocytes; urine sugar chromatogram $^{\text {UA, sugar chromatogram }}$ \\
Fatty acid oxidation disorders $^{\mathrm{b}, \mathrm{c}}$ & Blood acylcarnitine analysis, urinary OA \\
$\begin{array}{c}\text { Mitochondrial respiratory chain } \\
\text { deficiency }\end{array}$ & Blood lactate, pyruvate, AA; urinary lactate; DNA-analysis mtDNA depletion, POLG mutations \\
$\alpha 1$-antitrypsin deficiency & Blood $\alpha 1$-antitrypsin \\
\hline
\end{tabular}

$A A$ Amino acids, $O A$ organic acids

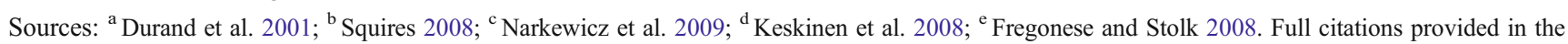
References section

born at $41^{+1}$ weeks gestation (birth weight 2,190 g, below $\mathrm{Z}-2.5 \mathrm{SD}$; Apgar-scores 5-6-8). The umbilical cord $\mathrm{pH}$ of 7.19 quickly normalized after admission to the neonatal ward. A cerebral CT revealed a right parietal fracture with edema without intracerebral hemorrhages, compatible with cerebral contusion due to complicated delivery.

At 5 days of age, the child started vomiting, and became lethargic and hypotonic. At physical examination, slow symmetric movements and absent orienting and acoustical blink reflexes were noted. She was transferred to the neonatal intensive care unit of a University Medical Center. Laboratory evaluation showed liver parameter concentrations of ALT $96 \mathrm{U} / \mathrm{L}(<45 \mathrm{U} / \mathrm{L})$ and $\gamma \mathrm{GT} 306 \mathrm{U} / \mathrm{L}(<50 \mathrm{U} / \mathrm{L})$ (reference values in parentheses; AST not determined). After cessation of paracetamol, liver parameters decreased to ALT $13 \mathrm{U} / \mathrm{L}$ and $\gamma$ GT $35 \mathrm{U} / \mathrm{L}$, respectively. Metabolic laboratory evaluations were not performed. Brain MRI revealed bilateral frontal and frontoparietal hemorrhages, with normal myelinization and anatomy. She was discharged after 16 days.

At follow-up, she grew along the -2 SD curve, and was delayed in developmental milestones. At 17 months of age, she presented with fever without clear focus, refusal of feeding, persistent vomiting, and diffuse itching. She was alert, anicteric, and without abnormalities on physical examination. Laboratory analysis showed the following results (reference values in parentheses): leukocytes $27.5 \times$ $10^{9} / \mathrm{L}\left(4.5-12.0 \times 10^{9} / \mathrm{L}\right)$, ESR $50 \mathrm{~mm} / \mathrm{h}(<3-13 \mathrm{~mm} / \mathrm{h})$, hemoglobin $5.7 \mathrm{mmol} / \mathrm{L}(6.5-8.4 \mathrm{mmol} / \mathrm{L})$, glucose $5.4 \mathrm{mmol} / \mathrm{L}(4.0-7.8 \mathrm{mmol} / \mathrm{L})$, creatinin $22 \mu \mathrm{mol} / \mathrm{L}(18-$ $35 \mu \mathrm{mol} / \mathrm{L})$, urea $1.2 \mathrm{mmol} / \mathrm{L}(1.8-6.7 \mathrm{mmol} / \mathrm{L})$, total bilirubin $118 \mu \mathrm{mol} / \mathrm{L}(3-14 \mu \mathrm{mol} / \mathrm{L})$, conjugated bilirubin $109 \mu \mathrm{mol} / \mathrm{L}(1-4 \mu \mathrm{mol} / \mathrm{L})$, albumin $21 \mathrm{~g} / \mathrm{L}(35-55 \mathrm{~g} / \mathrm{L})$, AST 1,581 U/L $(<40 \mathrm{U} / \mathrm{L})$, ALT $2,070 \mathrm{U} / \mathrm{L}(<45 \mathrm{U} / \mathrm{L})$, $\gamma \mathrm{GT} 192 \mathrm{U} / \mathrm{L}(<50 \mathrm{U} / \mathrm{L})$, alkaline phosphatase $601 \mathrm{U} / \mathrm{L}$
(55-250 U/L), LDH 1,087 U/L (<200 U/L), PTT 62 s $(9$ $12 \mathrm{~s})$, and APTT $62 \mathrm{~s} \mathrm{(23-33} \mathrm{s).} \mathrm{Arterial} \mathrm{blood} \mathrm{gas} \mathrm{analysis}$ showed pH 7.45 (7.35-7.45), pCO2 $5.2 \mathrm{kPa}(4.6-6.0 \mathrm{kPa})$, $\mathrm{HCO} 3-26.6 \mathrm{mmol} / \mathrm{L}(21-25 \mathrm{mmol} / \mathrm{L})$, and $\mathrm{BE}+2.7(-3.0$ to +3.0$)$. NH3 concentration was $114 \mu \mathrm{mol} / \mathrm{L}(15-45 \mu \mathrm{mol} / \mathrm{L})$. Abdominal ultrasound revealed no abnormalities.

An underlying metabolic disorder was suspected and the child was eventually referred to the University Medical Center Groningen (UMCG), so that, if necessary, liver transplantation could be performed as soon as possible. Metabolic analysis revealed glutamine 1,184 $\mu \mathrm{mol} / \mathrm{L}$ (335$810 \mu \mathrm{mol} / \mathrm{L})$, citrulline $1,442 \mu \mathrm{mol} / \mathrm{L}(<50 \mu \mathrm{mol} / \mathrm{L})$, and arginine $23 \mu \mathrm{mol} / \mathrm{L}(10-110 \mu \mathrm{mol} / \mathrm{L})$, and an urinary orotic acid excretion of $656 \mu \mathrm{mol} / \mathrm{mmol}$ creatinine (undetectable in healthy subjects). She was diagnosed with citrullinemia type I. Treatment was started with intravenous infusion of glucose, L-arginine, and oral sodium benzoate. Two days later, enteral feeding with restriction of natural protein intake was started. Concentrations of ammonia and transaminases normalised within a few days and 3 weeks, respectively. The child showed a marked clinical improvement. Incorporation of ${ }^{14} \mathrm{C}$-citrulline in fibroblasts was reduced to $7 \%$ of intra-assay control. DNA analyses are pending.

\section{Patient 2}

Patient 2 was a male Caucasian born to non-consanguineous parents. Patient 2 was born in the same district hospital as patient 1 , at $38^{+1}$ weeks after an uneventful gestation and delivery, with birth weight 2,680 g ( $\mathrm{Z}-1.3 \mathrm{SD}$ ), and Apgar scores 9 and 10.

At 22 months of age, he presented with episodic vomiting since 3 months, not obviously related to feeding, 
with a frequency varying from daily to weekly. Further history revealed increased fatigue, and a mild growth retardation since the age of 8 months. Concerns were raised about his development, since he was not able to walk without support nor to throw a ball without losing balance. At physical examination, the child was well and without abnormalities. Laboratory results revealed leukocytes $10.7 \times$ $10^{9} / \mathrm{L}$, thrombocytes $378 \times 10^{9} / \mathrm{L}\left(150-350 \times 10^{9} / \mathrm{L}\right), \mathrm{Hb}$ $7.2 \mathrm{mmol} / \mathrm{L}$, glucose $4.9 \mathrm{mmol} / \mathrm{L}, \mathrm{Na}+138 \mathrm{mmol} / \mathrm{L}(138$ $146 \mathrm{mmol} / \mathrm{L}), \mathrm{K}+4.3 \mathrm{mmol} / \mathrm{L}(4.1-5.5 \mathrm{mmol} / \mathrm{L}), \mathrm{Ca} 2+$ $2.38 \mathrm{mmol} / \mathrm{L}(2.20-2.60 \mathrm{mmol} / \mathrm{L})$, phosphate $1.58 \mathrm{mmol} / \mathrm{L}$ $(1.45-2.10 \mathrm{mmol} / \mathrm{L})$, albumin $33 \mathrm{~g} / \mathrm{L}$, AST $206 \mathrm{U} / \mathrm{L}$, ALT $323 \mathrm{U} / \mathrm{L}$, and urea $2.5 \mathrm{mmol} / \mathrm{L}$, capillary blood gas analysis pH 7.47 (7.32-7.42), pCO2 $3.8 \mathrm{kPa}(5.5-6.8 \mathrm{kPa}), \mathrm{HCO} 3-$ $20.2 \mathrm{mmol} / \mathrm{L}(24-28 \mathrm{mmol} / \mathrm{L})$, and $\mathrm{BE}-2.1 \mathrm{mmol} / \mathrm{L}(-3.0$ to +3.0), with NH3 $210 \mu \mathrm{mol} / \mathrm{L}$. Abdominal X-ray, barium enema, abdominal ultrasound, screening results of viral hepatitis and toxoplasmosis, and triple feces test were normal.

The patient was referred to an University Medical Center considering an urea cycle disorder. As liver function parameters deteriorated, the patient was referred the same day to the UMCG for liver transplantation. Laboratory evaluations revealed lactate $2.1 \mathrm{mmol} / \mathrm{L}(<2.0 \mathrm{mmol} / \mathrm{L})$, albumin $37 \mathrm{~g} / \mathrm{L}$, AST $757 \mathrm{U} / \mathrm{L}$, ALT 1,315 U/L, $\gamma \mathrm{GT}$ $38 \mathrm{U} / \mathrm{L}$, alkaline phosphatase $285 \mathrm{U} / \mathrm{L}$, INR $1.6(0.8-1.3)$, APTT $35 \mathrm{~s}$, arterial blood gas analysis $\mathrm{pH} 7.38$, with $\mathrm{pCO} 2$ $4.8 \mathrm{kPa}$, and $\mathrm{HCO}^{-}-21 \mathrm{mmol} / \mathrm{L}, \mathrm{NH} 3210 \mu \mathrm{mol} / \mathrm{L}$, glutamine $539 \mu \mathrm{mol} / \mathrm{L}$, citrulline $1,963 \mu \mathrm{mol} / \mathrm{L}$, and arginine $51 \mu \mathrm{mol} / \mathrm{L}$. Urine analysis revealed an orotic acid excretion of $1,315 \mu \mathrm{mol} / \mathrm{mmol}$ creatinine. The boy was diagnosed with citrullinemia type I. Treatment was started with intravenous infusion of glucose and L-arginine, oral sodium benzoate, and restriction of natural protein intake. Within 2 days, the child improved markedly, and blood concentrations of ammonia and liver parameters normalized. Incorporation of ${ }^{14} \mathrm{C}$-citrulline in fibroblasts was reduced to $14 \%$ of intra-assay control. DNA analysis revealed the c.685del8bp (fs232X) and c.815G > A (p.R272H) mutations in the ASS-gene.

\section{Discussion}

To our knowledge, these two Caucasian patients with citrullinemia type I are the first two presenting with acute liver failure for which liver transplantation was considered. Thus far, acute liver failure as a presentation of citrullinemia type I has been reported once, in a patient diagnosed during pregnancy (Dimmock et al. 2008). Pediatric acute liver failure may be defined as "hepatic necrosis resulting in loss of liver function within weeks or a few months of the onset of clinical liver disease" (Whitington et al. 2008). In our patients, synthetic liver function was compromised, as evident from the coagulopathy and hypoalbuminemia present in both, within the time frame mentioned in the definition. This validates the diagnosis of acute liver failure in our patients.

Citrullinemia type I is caused by argininosuccinate synthetase deficiency (E.C. 6.3.4.5), one of the six enzymes that constitute the urea cycle. Urea cycle disorders usually present with feeding problems, lethargy, convulsions, coma, and death during the first days of life (Brusilow and Horwich 2001). In addition, milder presentations at a later age with failure to thrive, neurological symptoms, developmental delay and/or behavioral disorders have also been described (Summar and Tuchman 2001).

In urea cycle disorders, acute liver failure is not generally considered to be a presenting symptom (Saudubray et al. 2002; Endo et al. 2004; Olpin 2010). However, in contrast to a statement made in a recent report (Olpin 2010), it should be acknowledged that urea cycle disorders can present with elevated transaminases and other biochemical signs of liver pathology. In urea cycle disorders other than citrullinemia type I, acute liver failure has occasionally been reported as the presenting symptom (Keskinen et al. 2008; Durand et al. 2001). The pathogenesis of liver dysfunction in urea cycle defects is unknown. It seems to be unrelated to the specific enzymatic defect, intermediary metabolites, or the number of hyperammonemic episodes, and may occur without concomitant hyperammonemia (Zamora et al. 1997; Kleijer et al. 2002; Mori et al. 2002).

Retrospectively, one might suggest that the neurological deterioration at day 5 in patient 1 was related to citrullinemia type I. Blood ammonia was never measured in this period, but she improved without any specific treatment, and also, retrospectively, the cerebral MRI performed at that time did not show abnormalities consistent with citrullinemia type I.

In this report, we emphasize urea cycle disorders as a cause of acute liver failure, particularly citrullinemia type I. In $40-50 \%$ of patients presenting with acute liver failure, an etiological diagnosis is not made (Squires 2008; Dhawan 2008). Urea cycle disorders may be underestimated as a cause of acute liver failure. Our case report shows that citrullinemia type I should be included in the differential diagnosis of children presenting with acute liver failure. The presentations of these two infants stress the importance of urgent and thorough metabolic investigations in such patients. Importantly, hyperammonemia in children with acute liver failure may be caused by urea cycle disorders, rather than be secondary to liver failure. An overview of inborn errors of metabolism that may lead to acute liver failure and associated investigations is presented in Table 1.

In conclusion, acute liver failure in children may be caused by citrullinemia type I and other inborn errors of metabolism. Adequate diagnosis and treatment may prevent progression of liver failure and liver transplantation. 
Acknowledgement The authors would like to acknowledge Prof. Dr. J. Häberle for DNA analysis.

Open Access This article is distributed under the terms of the Creative Commons Attribution Noncommercial License which permits any noncommercial use, distribution, and reproduction in any medium, provided the original author(s) and source are credited.

\section{References}

Brusilow SW, Horwich AL (2001) Urea cycle enzymes. In: Scriver CR, Beaudet AL, Sly WS, Valle D (eds) The metabolic and molecular bases of inherited disease. McGraw-Hill, New-York, pp 1667-1709

Dhawan A (2008) Etiology and prognosis of acute liver failure in children. Liver Transplant 14:80-84

Dimmock DP, Trapane P, Feigenbaum A et al (2008) The role of molecular testing and enzyme analysis in the management of hypomorphic citrullinemia. Am J Med Genet 146A:2885-2890

Durand P, Debray D, Mandel R et al (2001) Acute liver failure in infancy: a 14-year experience of a pediatric liver transplantation center. J Pediatr 139:871-876

Endo F, Matsuura T, Yanagita K, Matsuda I (2004) Clinical manifestations of inborn errors of the urea cycle and related metabolic disorders during childhood. J Nutr 134:1605-1609

Fregonese L, Stolk J (2008) Hereditary alpha-1-antitrypsin deficiency and its clinical consequences. Orphanet J Rare Dis 3:16
Keskinen P, Siitonen A, Salo M (2008) Hereditary urea cycle diseases in Finland. Acta Paediatr 97:1412-1419

Kleijer WJ, Garritsen VH, Linnebank M et al (2002) Clinical, xenzymatic, and molecular genetic characterization of a biochemical variant type of argininosuccinic aciduria: prenatal and postnatal diagnosis in five unrelated families. J Inherit Metab Dis 25:399-410

Mori T, Nagai K, Mori M et al (2002) Progressive liver fibrosis in late-onset argininosuccinate lyase deficiency. Pediatr Dev Pathol 5:597-601

Narkewicz MR, Dell Olio D, Karpen SJ et al (2009) Pattern of diagnostic evaluation for the causes of pediatric acute liver failure: an opportunity for quality improvement. J Pediatr 155:801-806

Olpin SE (2010) Metabolic disorders presenting as liver disease. Paed Child Health 20:1-6

Saudubray JM, Nassogne MC, de Lonlay P, Touati G (2002) Clinical approach to inherited metabolic disorders in neonates: an overview. Semin Neonatol 7:3-15

Squires RH (2008) Acute liver failure in children. Semin Liver Dis 28:153-166

Summar M, Tuchman M (2001) Consensus statement from a conference for the management of patients with urea cycle disorders. J Pediatr 138:S1-S5

Whitington PF, Alonso EM, Squires RH (2008) Acute liver failure. In: Kelly D (ed) Diseases of the liver and biliary system in children. Wiley-Blackwell, Oxford, pp 169-185

Zamora SA, Pinto A, Scott RB, Parsons HG (1997) Mitochondrial abnormalities of liver in two children with citrullinaemia. J Inherit Metab Dis 20:509-516 